\title{
Effect of Methamphetamine on Embryonic Development in Rats
}

\author{
Changlei $\mathrm{Li}^{1, \mathrm{a}}, \mathrm{Xiji}$ Shu ${ }^{1, \mathrm{~b}}$, Xiaoqing Chen ${ }^{1, \mathrm{c}}$, Yuwei Liu ${ }^{1, \mathrm{~d}}$, Huiling $\mathrm{Yi}^{1, \mathrm{e}}$, \\ Baomiao $\mathrm{Ma}^{2, \mathrm{f}_{*}}$ \\ ${ }^{1}$ School of Medicine, Jianghan University, Wuhan 430056, China \\ ${ }^{2}$ Wuhan Institutes of Biomedical Sciences, Jianghan University, Wuhan 430056, China \\ aemail:licl.jhun@foxmail.com; ${ }^{b}$ email: shuxiji@sina.com; 'email:8298921@qq.com; ${ }^{\text {demail: }}$ \\ 304077545@qq.com; eemail: 349351667@qq.com; 'email: mabm.whibs@aliyun.com
}

${ }^{*}$ Corresponding author

\begin{abstract}
To study the effect of methamphetamine (METH) on embryonic development in rats. The number of male SD rats and female SD rats was 50 respectively, male and female rats were taken 30 respectively, which were used to establish the METH chronic poisoning rat model, after that, model animals were randomly divided into 2 groups $(n=10)$. The other 20 male rats and 20 female rats whom were not used for modeling as the control group, which by gender were randomly divided into 2 groups $(\mathrm{n}=10)$. Male and female rats were randomly mating in accordance with the ratio of 1:1, whom be divided into four groups: A group (both male and female rats were exposed whom be mated), B group (male exposed rats were mated with female rats whom not be exposed), C group (female exposed rats were mated with male rats whom not be exposed), D group (both male and female rats were not exposed whom be mated, control group). After mated 24h, detection the pregnancy rate of female rats were $98 \%$, 2-cell stage embryos produced by rats of each group were cultured in vitro. There were no significant differences in the number of 2-cell stage embryos produced by rats of each group $(\mathrm{P}>0.05)$. The number of 4-cell stage embryos in group A was lower than that in group $\mathrm{D}(\mathrm{P}<0.05)$. The number of 8-cell stage and 16-cell stage embryos in group $\mathrm{A}, \mathrm{B}$ and $\mathrm{C}$ were significant differences than those in group $\mathrm{D}(\mathrm{P}<0.05$ or $\mathrm{P}<0.01)$. The number of morula stage and blastula stage embryos in group $\mathrm{A}, \mathrm{B}$ and $\mathrm{C}$ were significant differences than those in group $\mathrm{D} \quad(\mathrm{P}<0.01)$. Methamphetamine can affects the embryo development of rat, especially have a greater impact to embryos development by both male and female rats were exposed whom be mated.
\end{abstract}

Keywords: Methamphetamine, Rat, Embryos development, Cleavage

\section{Introduction}

Methamphetamine commonly known as "ice", with a strong addiction, excitability of the central nervous system, hallucinogenic, appetite suppression and sympathetic energy effect, can be an addiction; the high dose can lead to poisoning and death ${ }^{[1-8]}$. Previous studies have shown that abuse METH can cause to toxic damage of endocrine system, digestive system, cardiovascular and cerebrovascular system, nervous system, urinary and reproductive system, research focused on studies the central nervous system toxicity and addiction dependence mechanism of METH. However, there is no report about the effect of METH on the reproductive system, especially on the embryos development by male and female rats were exposed whom be mated. 


\section{Materials and methods}

Animal. The number of male SPF SD rats and female SPF SD rats was 50 respectively and their body weight were $220 \pm 20 \mathrm{~g}$, whom were conventional single cage breed in barrier environment, eating and drinking with free state.

Reagents and instruments. Hydrochloric acid METH, 0.9\% saline, petri dishes, carbon dioxide incubator, fetal calf serum (FBS), tissue culture medium199(TCM-199), mature medium: TCM-199+10\%FBS $+5 \mu \mathrm{g} / \mathrm{mL}$ (follicle-stimulating hormone, FSH). Embryo culture medium: TCM-199+10\% FBS. PBS: $0.02 \mathrm{~g} \quad \mathrm{KCl}+0.8 \mathrm{~g} \quad \mathrm{NaCl}+0.144 \mathrm{~g} \quad \mathrm{Na}_{2} \mathrm{HPO}_{4}+0.02 \mathrm{~g} \quad \mathrm{NaH}_{2} \mathrm{PO}_{4}+0.006 \mathrm{~g}$ penicillin $+0.01 \mathrm{~g}$ streptomycin.

Modeling, packet administration and obtain rat embryos. Experimental grouping and modeling: fifty male SD rats were divided into experimental group (used to make the METH chronic poisoning rat model, $n=30)$ and control group $(n=20)$, fifty female SD rats were divided into experimental group (used to make the METH chronic poisoning rat model, $n=30$ ) and control group $(\mathrm{n}=20)$. The hydrochloric acid METH was dissolved in $0.9 \%$ physiological saline to make $1 \mathrm{mg} / \mathrm{ml}$ solution of METH physiological saline. The experimental group rats were intraperitoneal injection solution of METH physiological saline, the control group rats were intraperitoneal injection with the same volume physiological saline. The dose was $5 \mathrm{mg} / \mathrm{kg} \bullet \mathrm{BW}$, the solution was injected at 8:00 pm every day, continuous administration for 7 weeks, a total of 49 times, establish the METH chronic poisoning rat model.

The experimental group rats showed obvious toxic reaction after half an hour of injecting METH solution. These responses were consistent with pharmacological characteristics of METH poisoning, which indicated that establish the METH chronic poisoning rat model with successfully. Through detection, the number of successfully model in male and female rats were 27 and 25 , and each of them be taken 20 as the reserve.

20 male and 20 female METH chronic poisoning model rats were respectively randomly divided into two groups, 10 rats in each group. 20 male and 20 female control group rats were respectively randomly divided into two groups, 10 rats in each group.

In the estrus interval female rats, intraperitoneal injection PMSG 7.5U, after 46-48h, intraperitoneal injection $\mathrm{HCG}$ 7.5U, and then take them mating with the male rat in accordance with the ratio of 1:1. After that, them be divided into four groups, A group (both male and female rats were exposed whom be mated), B group (male exposed rats were mated with female rats whom not be exposed), C group (female exposed rats were mated with male rats whom not be exposed), D group (both male and female rats were not exposed whom be mated, control group).

After with the cage 24 hours, check those who have the tamponade as the first day of pregnancy. After injection of HCG 40-44h, female rats of each group were divided by group distinction, whom were sacrificed in the sterile environment and obtain their ovaries (10 per group), removal of ovarian mesangial and fallopian tubes and other excess tissues, and then ovaries be washed in saline which containing double-antibody for 2 to 3 times and be washed twice in sterile PBS buffer, after that, the ovaries were placed in D-PBS. The rat embryos were detached by using prickly needle under the stereomicroscope, select the good quality embryos which have some features: cytoplasm uniform, there are intact zona pellucida and zona pellucida is surrounded by more than 3 layers granulosa cells, transfer them into the $35 \mathrm{~mm}$ disposable plastic petri dishes which contain $30 \mu \mathrm{L}$ mature embryo culture liquid droplets that beforehand preheat for $1 \mathrm{~h}$ and covered with paraffin oil, 8-10 embryos were placed in per droplet. They were matured in vitro at $37^{\circ} \mathrm{C}$ carbon dioxide incubator, observation the successful number of each group embryos development from 2 cells to blastula stage. 
Statistical Analysis. Using SPSS 13.0 software for statistical analysis of the obtained data, the results of indicators were expressed by $\overline{\mathrm{x}} \pm \mathrm{s}$, significance test using the $\mathrm{t}$ test and ANOVA. With $P<0.05$ was considered statistically significant and $P<0.01$ as statistically significant difference.

\section{Results}

Table 1. The number of each group embryos development from 2 cells to blastula stage

\begin{tabular}{|c|c|c|c|c|c|c|}
\hline & 2 cell stage & 4 cell stage & 8 cell stage & 16 cell stage & morula stage & blastula stage \\
\hline Group A & 102 & $85^{\mathrm{a}}$ & $62^{\mathrm{b}}$ & $40^{\mathrm{b}}$ & $21^{\mathrm{b}}$ & $13^{\mathrm{b}}$ \\
\hline Group B & 113 & 101 & $87^{\mathrm{a}}$ & $65^{\mathrm{a}}$ & $38^{\mathrm{b}}$ & $22^{\mathrm{b}}$ \\
\hline Group C & 109 & 98 & $74^{\mathrm{a}}$ & $51^{\mathrm{b}}$ & $28^{\mathrm{b}}$ & $9^{\mathrm{b}}$ \\
\hline $\begin{array}{c}\text { Group D } \\
\text { (control group) }\end{array}$ & 120 & 116 & 109 & 94 & 88 & 76 \\
\hline
\end{tabular}

Note: compared with the control group, ${ }^{\mathrm{a}} \mathrm{P}<0.05,{ }^{\mathrm{b}} \mathrm{P}<0.01$

There were no significant differences in the number of 2-cell stage embryos produced by rats of each group ( $\mathrm{P}>0.05)$. The number of 4-cell stage embryos in group A was lower than that in group $\mathrm{D}(\mathrm{P}<0.05)$, and which in group $\mathrm{B}$ and $\mathrm{C}$ was not significantly different from that in group $\mathrm{D}$ $(\mathrm{P}>0.05)$. The number of 8-cell stage and 16-cell stage embryos in group $\mathrm{A}, \mathrm{B}$ and $\mathrm{C}$ were significant differences than those in group $\mathrm{D}(\mathrm{P}<0.05$ or $\mathrm{P}<0.01)$. The number of morula stage and blastula stage embryos in group $\mathrm{A}, \mathrm{B}$ and $\mathrm{C}$ were significant differences than those in group $\mathrm{D}$ $(\mathrm{P}<0.01)$.

\section{Discussion}

In the development process, embryos are extremely sensitive to genetic factors and the developmental environment, at this time, various harmful factors all can lead to embryo damage, or even loss ${ }^{[9-10]}$. The results showed that there was no significant difference in the number of 2-cell stage embryos produced by both male and female rats all exposed whom be mated, either male or female rat be exposed whom be mated, both male and female rats were all not exposed whom be mated, with the embryo cleavage differentiation, the number of embryo apoptosis in the infected group rat was higher than that in the uninfected group rat, the number disparities is particularly evident in the morula and blastula stage, and the point of view from embryonic development of A group and $\mathrm{C}$ group, we known that female rats be infected drug, its embryonic apoptosis faster. The results showed that METH was more harmful to females and directly affect the developmental quality of their offspring. Male and female donors all are exposed to which have more harmful to its individual growth of offspring.

METH can directly act on the central nervous system and endocrine system of female and male individuals, causing to reproductive hormone secretion disorder and the expression decreased significantly of IGF-II mRNA in villi and decidua, affect placental function and hinder embryonic development, which lead to loss of early embryos or developmental stagnation ${ }^{[11-12]}$.

Embryonic development is the process of the combined action of various factors; many factors will cause an adverse effect. The mechanism of drugs how to affect the embryonic development is not clear, still requires further research and study. To explore the influence of various factors on human embryonic development, which have the great significance to the development technology of natural pregnancy and assisted reproductive technology. 


\section{Acknowledgements}

This work was supported by the National Natural Science Foundation of China (81373725).

\section{References}

[1] Ma Baomiao, Yue Kai, Ru Qin, et al. Effects of Levo-tetrahydropalmatine on Heroin Reinforcement in Rats [J]. Acta Med Univ Sci Technol Huzhong, 41(2012), p. 573-576.

[2] King GK, Elinwood EH. Amphetamine and other stimulants [M]. In: Loxinson JH, Ruiz P, Millman RB, et al, eds. Substance abuse. 3rd ed. Baltimore: Williamsand wilkins, 1997, p. 207-221.

[3] Simon SL, Domier C, Carnell J, et al. Cognitive impairment in dividuals currently using methamphetamine [J]. Am J Addict, 9(2000), p. 222-231.

[4] Wilson JM, Kalasinsky KS, Levey AI, et al. Striataldopamine nerve terminal markers in human chronic methamphetamine users [J]. Nat Med, 2(1996), p. 699-703.

[5] Yui K, Goto K, Ikemoto S, et al. Neurobiological basis of replace prediction in stimulant-induced psychosis and schizophrenia: the role of sensitization [J]. Mol Psychiatry, 4(1999), p. 512-523.

[6] Kramer JC, Fischman VS, Littlefield DC. Amphetamine abuse. Pattern and effects of high doses taken intravenously [J]. JAMA, 201(1967), p. 305-309.

[7] Volkow ND, Chang L, Wang GJ, et al. Higher cortical and lower subcortical metabolism in detoxified methamphetamine abusers [J]. Am J psychiatry, 158(2001), p. 383-439.

[8] Conci F, Dangelo V, Tampieri D, et al. Intracerebral hemorrhage and angiographic beading following amphetamine abuse [J]. Ital J Neural, 9(1988), p. 77-81.

[9] CHEN Xi-jing, HUANG He-feng. Effects of chemical factors on embryonic development [J].

Chinese Jo urnal of M a te rnal and Child H ealth Research, 17(2006), p. 176-179.

[10] Somi S S. Cytokines during early pregnancy of mammals [J]. Animal Reproduction Science, 75(2003), p. 73-84.

[11] Islam MN, Jasmine K, Kong Sn Molh A, et al. Histopathological studies of cardiac lesions after long term administration of methamphetamine in high dosage-Part II [J]. Leg Med (Tokyo). 11 (2009), p. 147-150.

[12] LIANG Jia-pei, QIAO Dong-fang, QU Yi-hong, et al. Effect of Methamphetamine on Myocardial Damage in Rats [J]. J Toxicol August, 28(2014), p. 291-294. 